\title{
O Programa Institucional de Bolsas de Iniciação à Docência: um novo paradigma para a formação de professores?
}

Paulo Ricardo da Silva Rosa paulo.rosa@ufms.br

Universidade Federal de Mato Grosso do Sul (UFMS), Campo Grande, Mato Grosso do Sul, Brasil.

\section{RESUMO}

Neste artigo, apresentamos o Programa Institucional de Bolsas de Iniciação à Docência e a concepção de formação de professores que orienta sua implantação na Universidade Federal de Mato Grosso do Sul, baseada na ideia que o docente se constrói, como sujeito epistemológico, na ação docente e que a escola deve ser um campo de formação. Baseada no tripé Reflexão - Ação - Reflexão Sobre a Ação, a estratégia de formação busca desenvolver nos acadêmicos a competência de refletir sobre sua ação, integrando esta reflexão ao processo formativo do futuro professor. Propomos o PIBID como um novo paradigma para a formação docente em cursos de formação inicial.

PALAVRAS-CHAVE: Pibid. Formação docente. 


\section{INTRODUÇÃO}

O modelo atual de formação docente na maior parte dos cursos de licenciatura é baseado na oferta de disciplinas agrupadas em cinco eixos:

a) conhecimentos a serem ensinados (a Física, a Matemática, os conteúdos linguísticos etc.);

b) conhecimentos sobre o como ensinar (Didática);

c) conhecimentos contingentes ao ensinar (Psicologia do Desenvolvimento, Sociologia da Educação, Políticas Públicas etc.);

d) prática de Ensino e de Estágio;

e) componentes curriculares de formação geral (disciplinas opcionais, Atividades Complementares etc.).

A interação com as escolas acontece, em geral, somente nas atividades de estágio, na segunda metade do curso. Ou seja, o futuro professor passa de dois a três anos no curso de formação sem ter contato com o ambiente no qual desempenhará suas funções.

Além disso, há também desarticulação entre os diferentes eixos de formação. Observe-se que, na formulação original da Prática de Ensino como Componente Curricular, a ideia era de que a reflexão sobre o ensino dos conteúdos a serem ensinados deveria permear as o curso de maneira geral e as disciplinas nas quais os estudantes aprendem os próprios conteúdos a serem ensinados (BRASIL, 2001).

Esse modelo de curso acarreta vários problemas para a formação. Primeiro, pela centralidade na sala de aula. Segundo, pela ênfase na racionalidade técnica como única fonte dos conhecimentos para formação docente. Terceiro, por desconsiderar o corpo de conhecimentos gestado na própria escola a partir das vivências e convergências construídas na prática docente e nas interações entre os diferentes agentes atuantes no campo escolar.

Para superar esses problemas, propomos neste trabalho, que o modelo desenvolvido nos grupos do Programa Institucional de Bolsas de Iniciação à Docência (PIBID) pode se constituir em um novo paradigma para a organização curricular dos cursos de formação de professores.

\section{O PIBID E UMA CONCEPÇÃO DE A FORMAÇÃO PARA A DOCÊNCIA}

Inicialmente concebido pela Secretaria de Ensino Superior do Ministério da Educação (SeSU/MEC), o iniciou, de fato, no ano de 2008, quando passou para o gerenciamento da Coordenação de Aperfeiçoamento do Pessoal de Nível Superior (CAPES), que havia recebido a incumbência de coordenar e desenvolver os projetos ligados à formação de professores. O primeiro Edital para seleção de projetos, lançado no ano de 2008, tinha por foco projetos ligados às licenciaturas das áreas de Ciências Biológicas, Matemática, Física e Química e era direcionado apenas às Instituições Federais de Ensino Superior. A esse Edital seguiram outros, aumentando abrangência do programa, primeiro para as instituições de ensino superior públicas fora da esfera federal e, posteriormente, para todas as instituições de ensino superior. Marco importante no desenvolvimento do PIBID 
foi o PIBID - Diversidade, voltado para licenciaturas indígena, do campo e outras de mesma natureza, por reconhecer as especificidades desses cursos.

O PIBID é estruturado na forma de projetos desenvolvidos pelas instituições de ensino superior, coordenado por um docente da IES, o Coordenador Institucional e, na versão atual do programa, por uma equipe de docentes da IES, os Coordenadores de Gestão. Em cada projeto são desenvolvidos subprojetos ligados aos cursos de licenciatura e a escolas da rede de educação básica (as escolas parceiras), os quais são compostos por um ou mais Coordenadores de Área, docente do curso, um ou mais Supervisores, professores das escolas parceiras, e alunos dos cursos de licenciatura (bolsistas de Iniciação à Docência ${ }^{1}$ ).

Desde o primeiro Edital, o PIBID tem como objetivos (BRASIL, 2007; 2013):

I - Incentivar a formação de docentes em nível superior para a educação básica;

II - Contribuir para a valorização do magistério;

III - Elevar a qualidade da formação inicial de professores nos cursos de licenciatura, promovendo a integração entre educação superior e educação básica;

IV - Inserir os licenciandos no cotidiano de escolas da rede pública de educação, proporcionando-Ihes oportunidades de criação e participação em experiências metodológicas, tecnológicas e práticas docentes de caráter inovador e interdisciplinar que busquem a superação de problemas identificados no processo de ensino aprendizagem;

V - Incentivar escolas públicas de educação básica, mobilizando seus professores como co-formadores dos futuros docentes e tornando-as protagonistas nos processos de formação inicial para o magistério;

VI - Contribuir para a articulação entre teoria e prática necessárias à formação dos docentes, elevando a qualidade das ações acadêmicas nos cursos de licenciatura;

VII - Contribuir para que os estudantes de licenciatura se insiram na cultura escolar do magistério, por meio da apropriação e da reflexão sobre instrumentos, saberes e peculiaridades do trabalho docente.

Em particular, nos interessam aqui os objetivos IV, V e VII, pois estão ligados a uma concepção de formação docente que iremos discutir adiante. Estes objetivos apontam para duas intencionalidades, nem sempre presentes nos cursos de formação de professores:

a) a formação de professores necessita ser desenvolvida tanto no campo teórico - prático, nas instituições formadoras, como no campo da prática profissional, a escola;

b) a incorporação no processo formativo dos conhecimentos ${ }^{2}$ docentes construídos pelos próprios docentes ao longo de suas práticas.

A proposta de formação de professores que embasa o PIBID é baseada na ideia de que o professor é formado por um conjunto de processos complexos e interdependentes. Se, por um lado, o professor precisa de qualificações técnicas, estas por si só não garantem sua formação integral, ou seja, não podemos restringir a formação de professores às normas propostas pela racionalidade 
técnica (GAUTHIER et al. 1997; SCHÖN 2000; ROSA, 2011). Não basta, para formar o futuro professor, municiá-lo com o conhecimento do conteúdo a ser ensinado e com as técnicas de ensino usuais. Como ser social, o futuro professor traz com ele um conjunto de concepções (muitas vezes não coordenadas e, outras tantas, implícitas) sobre o que é o ensino e o aprender, construídas ao longo dos seus anos de escola como aluno. Associadas a estas concepções, ele desenvolverá outras (muitas vezes congruentes com aquelas ideias iniciais) ao longo do seu curso de formação. Estas concepções influenciam fortemente o que ele fará como professor em sua sala de aula ${ }^{3}$ (TARDIF, 2007).

A dinâmica de sala de aula, por outro lado, é complexa, envolvendo interações entre professores e alunos e alunos e alunos, tanto no domínio da matéria (entendido como as interações de com objeto do conhecimento) como no domínio da classe, de natureza psicossocial, as quais envolvem, além da componente cognitiva, as componentes afetiva, emocional e social (GAUTHIER et al., 1997). Neste ambiente multifacetado, o professor tem que lidar com o produto da interação entre o que ele aprende no curso de formação de professores (Domínio da Matéria e Domínio da Classe) e as características da situação na qual está inserido. Na forma como são sistematizados e apresentados nos cursos de formação, esses conhecimentos apenas permitem que sejam formados esquemas de ação simplificados, construídos sobre situações idealizadas, as quais, muitas vezes, são esvaziadas dos aspectos mais problemáticos envolvidos nas interações em sala de aula, ou de uma forma mais geral, na escola ${ }^{4}$. Por conta disto, ao longo da vida profissional, o professor deve construir um novo corpo de conhecimentos, oriundo da interação entre o que the foi ensinado em sala de aula ao longo do curso de formação de professores e as situações do cotidiano pelas quais passa (interações com os alunos e colegas, inseguranças e medos pessoais, expectativas sociais, relações de poder e de classe na escola etc.).

É necessário, portanto, para que esse corpo de conhecimentos seja forjado ${ }^{5}$, que o futuro professor desenvolva a capacidade de refletir sobre suas ações. Aqui devemos apontar que não estamos defendendo a ideia do professor pesquisador, no sentido de que este professor exercerá a atividade de pesquisa em sala de aula nos moldes da academia (SCHÖN, 2000). O que defendemos é que o futuro professor desenvolva na ação a capacidade metacognitiva de pensar sobre o seu fazer, analisando este fazer a partir de diferentes perspectivas, mudando-o ou não. Não basta projetar a ação e desenvolvê-la. O processo formativo somente se completa com a reflexão que o futuro professor faz sobre o seu agir.

A ideia central do PIBID como projeto de formação de professores, tal como proposto institucionalmente (BRASIL, 2007; 2009; 2010a; 2010b) é a transformação do espaço escolar em um espaço de formação. Isto se dá por diversos canais formativos: atividades de ensino, vivência do espaço escolar em sua forma plena, convivência com docentes em serviço etc. Esse, a nosso ver é o principal diferencial do PIBID em relação a outros programas de formação de professores. Ao vivenciar o espaço escolar, com suas congruências, sinergias e contradições, o futuro professor se depara com situações ricas para o exercício de sua reflexão e o desenvolvimento daquelas capacidades que the permitirão o exercício da reflexão sobre sua prática no futuro. Ainda dentro desta lógica orientadora do processo formativo, a figura do Supervisor (um professor da escola que recebe uma bolsa para orientar as ações dos acadêmicos) é 
fundamental. Ele, o Supervisor, é o elemento de ligação entre a escola e a universidade, é o elemento articulador das ações na escola e, principalmente, é aquele profissional com experiência que vai orientar as ações dos acadêmicos no campo escolar (BOURDIEU; PASSERON, 1992). Além disso, o Supervisor é o elemento mediador entre os saberes produzidos na escola por seus docentes e os futuros professores.

Nosso ponto de vista quanto à formação de professores é que esta não deve ser entendida no seu sentido stricto sensu, associado à Didática da disciplina de formação. Cremos que reduzir a formação para a docência às atividades de ensino é reduzir a formação aos cânones da racionalidade técnica. Preferimos a concepção de formação que chamamos de lato sensu, aquela que engloba a Didática da Disciplina, mas que contempla outros momentos de formação, associados à construção da identidade docente e com a percepção do espaço escolar como campo político - ideológico. Nesta perspectiva, formar o futuro professor é expô-lo à atividade de docência em aulas compartilhadas ou de recuperação, por exemplo, mas também é levá-lo a refletir sobre a reunião de pais e mestres a qual assistiu.

Uma pergunta que se apresenta nesse ponto é: qual seria o conjunto de princípios orientadores que devam fazer parte do projeto de formação docente? Apresentaremos agora o conjunto que orienta a formação nos grupos do PIBID UFMS.

\section{O PROFESSOR É UM PROFISSIONAL AUTÔNOMO}

É necessário romper com a ideia de que ser professor é uma arte ou que as habilidades docentes não possam ser ensinadas. O curso de formação de professores deve ser projetado para fazer com que o futuro professor se aproprie dos conhecimentos e técnicas necessárias ao desempenho de suas funções na escola.

Esta afirmação não nega ou contradiz outra, comumente exposta, de que a atividade docente é localizada e historicamente situada e que, por esta característica, é sempre particular. Isto é verdade. Contudo, o futuro professor deve ser capacitado ao longo de sua formação na utilização das ferramentas intelectuais e técnicas que lhe permitam, primeiro, compreender este momento histórico particular no qual está inserido e as forças sociais que o moldaram, e, segundo, the possibilitem identificar quais as ferramentas e quais as possibilidades a sua disposição para a superação dos obstáculos que encontra.

Este profissional deve ter como sua principal característica a autonomia, entendida como a capacidade de construir soluções para situações não trabalhadas anteriormente e avaliar a eficácia destas soluções. Outro ponto importante sobre a autonomia é que ela não pode ser ensinada, devendo ser construída ao longo do processo de formação a partir do seu exercício.

Uma consequência natural desta característica de nossa concepção de formação é que as ações em um grupo PIBID devem privilegiar a análise das situações de ensino a partir dos conteúdos curriculares e dos saberes docentes sistematizados. Nestas análises, a visão dos acadêmicos de como as soluções devam ser construídas precisam ser o eixo condutor na elaboração destas ações. O exercício da autonomia passa pela reflexão por parte dos estudantes sobre 
suas ações, após o desenvolvimento das estratégias elaboradas por eles, não dadas pelo coordenador do grupo, portanto. O papel do Coordenador de Área deve ser o de um facilitador deste processo de tomada de consciência e desenvolvimento da autonomia.

\section{EXISTE UM CONJUNTO DE CONHECIMENTOS QUE CARACTERIZA O PROFISSIONAL PROFESSOR}

Um professor é caracterizado por ser detentor de um conjunto específico de conhecimentos que o qualificam para a função docente. Alguns destes conhecimentos são disciplinares (são exemplos os conhecimentos oriundos da Psicologia, da Sociologia, da Didática das áreas dos conhecimentos a serem ensinados e os próprios conhecimentos a serem ensinados) outros emergem da própria prática docente e são característicos da profissão docente (conhecimentos ligados à gestão do espaço da sala de aula, por exemplo). 0 projeto de formação de professores deve propiciar aos acadêmicos o contato com estes conhecimentos de forma articulada, contextualizada e reflexiva.

Em nossa visão, é a apropriação destes conhecimentos que torna alguém um professor. Não é a prática docente que define o professor como um profissional da docência, mas, sim, o conjunto de conhecimentos e saberes que orientam esta prática. Usando uma analogia, não é o ato de praticar uma incisão que torna alguém um médico, mas o que faz de alguém um médico é o domínio dos conhecimentos que orientam como realizá-la e que permitem a alguém identificar as situações nas quais ela é necessária.

A consequência dessa premissa para as ações dos grupos PIBID é a necessidade do planejamento das ações do grupo a partir do levantamento dos conhecimentos sistematizados sobre o tipo de situação a ser enfrentada pelos acadêmicos. Soluções de tipo senso comum não são aceitáveis.

É importante salientar que esse conhecimento docente tem múltiplas fontes, como discutiremos no próximo ponto.

\section{O CONJUNTO DE CONHECIMENTOS QUE CARACTERIZA O PROFISSIONAL PROFESSOR É COMPOSTO POR CONHECIMENTOS ACADÊMICOS E POR CONHECIMENTOS ORIUNDOS DA PRÁTICA DOCENTE}

O conhecimento docente tem duas fontes, não excludentes e não em oposição, mas complementares: os conhecimentos produzidos no âmbito das universidades e centros de pesquisa em Educação e em Ensino e os conhecimentos oriundos da prática docente. É a partir da prática docente que conhecimentos específicos e conectados com a realidade local emergem. Muitas vezes esse conhecimento não é sistematizado, mas ele existe e deve ser valorizado.

Observe-se que aqui pontuamos para duas origens dos conhecimentos docentes, não para sua dualidade. $O$ importante é a percepção de que estes conhecimentos têm, apenas, origens diferentes, formando uma totalidade 
PIBID devem ser planejadas. A afirmação corriqueira de que "a teoria na prática é outra" não é aceitável, como discutiremos mais adiante.

Na literatura atual de pesquisa e sobre a produção de docentes atuantes na rede da educação básica existe muito material a respeito da produção de conhecimento emergente da prática docente ${ }^{6}$. 0 estudo desta literatura deve ser parte integrante do processo de formação. A exploração dos conhecimentos locais (dos docentes da escola na qual as ações do projeto PIBID são desenvolvidas) também deve ser atividade corriqueira nos grupos do PIBID. A conexão destes conhecimentos, de diferentes origens, somente pode acontecer nos momentos de reflexão dentro dos grupos do PIBID, sendo parte integrante do processo formativo.

\section{A PARTE DOS CONHECIMENTOS ORIUNDOS DA PRÁTICA DOCENTE SOMENTE É ÚTIL QUANDO INCORPORADO A UM CORPO TEÓRICO QUE PERMITA A ESTE CONHECIMENTO SER SISTEMATIZADO E, PORTANTO, PASSÍVEL DE SER ENSINADO AOS FUTUROS PROFISSIONAIS PROFESSORES}

Os conhecimentos oriundos da prática somente podem ser úteis a um novo professor se ele puder ser sistematizado e ensinado a ele. Isto exige reflexão sobre as diferentes práticas docentes que originaram este saber. De nada adianta dizer ao futuro professor faça desta ou daquela maneira se não soubermos dizer a ele porque, ao realizar sua prática docente desta ou daquela forma, o resultado pretendido aparece. Sem esse conhecimento, não poderemos prever qual será o resultado da aplicação da prática em um contexto levemente diferente e a prática docente acontecerá por tentativa e erro. Como defenderemos no próximo item, a dicotomia Teoria - Prática é uma falsa dicotomia. O que deve ser buscada é uma relação dialética entre as duas componentes da formação.

A consequência dessa ideia, de uma relação dialética, é que a apropriação dos conhecimentos docentes construídos a partir da prática dos professores das escolas nas quais o PIBID atua não deve partir de uma apropriação acrítica destas práticas, mas deve ser precedida por uma reflexão sobre as condições sóciohistóricas que fizeram daquela prática uma prática de sucesso.

\section{NÃO EXISTE A DICOTOMIA TEORIA - PRÁTICA}

A Teoria e a Prática são aspectos da mesma entidade teórica, o saber docente. A Teoria e a Prática devem estar em uma relação dialética da qual o saber docente emerge como síntese.

A Teoria existe para dar suporte às observações do real e é construída a partir da reflexão sobre o real. A Prática, por sua vez, é a ação sobre o real orientada pela Teoria visando à modificação deste real. Sendo assim, a Teoria orienta a Prática, no sentido que lhe fornece o modus operandi e o modelo do real, e o resultado da ação prática, entendido como o resultado do processo reflexivo sobre a ação prática, aponta o que deve evoluir na Teoria (evoluir aqui é usado no sentido de ser modificado, passando de um estado a outro) melhorando desta forma nossa compreensão do real. 
Não existe Prática sem um referencial teórico (modelo de mundo) que a oriente. A ação por parte dos seres humanos é sempre uma ação orientada com base em um modelo do mundo. Este modelo de mundo é composto por conceitos, por relações entre estes conceitos e regras operacionais. O docente, mesmo quando age por tentativa e erro, age com base em um modelo de mundo (implícito muitas vezes). Prática sem modelo não existe.

O corolário desta afirmação é que as ações de formação dentro dos grupos do PIBID devem sempre partir da explicitação do modelo que orientará a ação, pela ação propriamente dita e pela reflexão sobre a ação desenvolvida, comparando a ação desenvolvida e seus resultados com as previsões do modelo inicial. O modelo inicial, por sua vez, deve ser construído buscando-se os conhecimentos curriculares e os conhecimentos docentes construídos a partir de suas práticas pelos docentes da escola na qual o projeto PIBID se desenvolve. Como defenderemos mais adiante, é no momento em que esta reflexão sobre a ação e seu enfrentamento com a Teoria é realizado que o processo formativo acontece. Não existe processo formativo sem tomada de consciência.

\section{PARA A FORMAÇÃO DOCENTE É INDISPENSÁVEL E FUNDAMENTAL A INTERAÇÃO COM O ESPAÇO ESCOLAR AO LONGO DO PROCESSO FORMATIVO}

O espaço escolar é o locus por excelência para a formação docente. A leitura de mundo no espaço escolar e a reflexão sobre ele são aspectos fundamentais da formação. Se concordarmos com Tardif (2007) de que a função docente é caracterizada como sendo uma função de interação entre seres humanos, ela somente pode ser apreendida no espaço no qual as interações entre seres humanos acontecem e pela vivência destas interações. Além disso, a inserção no espaço escolar dará ao futuro docente elementos que podem ajudá-lo a compreender o que é a função docente em todas as suas dimensões, não somente a dimensão do ensino e do contato com os alunos.

É importante salientar que o espaço escolar deve ser compreendido de forma ampla, não devendo ser reduzido à atividade de ensino em sala de aula ou a questões a ela relacionadas. O espaço escolar é amplo e diversificado, integrando aspectos intrínsecos (relações de poder, relações de classe, expectativas pessoais e coletivas etc.) e aspectos relacionais com o meio (ações externas sobre o espaço escolar). O espaço escolar é permeável e influenciado pelo que acontece na comunidade na qual a escola está inserida. A exploração de todos estes aspectos deve fazer parte das ações dos grupos do PIBID.

\section{O PIBID, COMO PROPOSTA DE FORMAÇÃO, BUSCA NO REAL DA ESCOLA SITUAÇÕES POTENCIALMENTE FORMADORAS PARA O FUTURO PROFISSIONAL PROFESSOR}

Este, talvez, seja o principal problema de definição teórica no PIBID desde a sua criação: como o PIBID se diferencia de outras ações formadoras no curso de licenciatura como o estágio e as práticas de ensino?

Na nossa visão, a principal diferenciação do PIBID em relação àquelas outras atividades é que no PIBID escolhemos as competências e habilidades que queremos que sejam desenvolvidas pelos acadêmicos e, então, escolhemos as 
situações necessárias na escola que exijam estas competências e habilidades e as elegemos como as situações de trabalho dos acadêmicos. As outras atividades de formação, como o Estágio, por exemplo, partem da lógica inversa: uma vez inserido na sua atividade docente na escola o estudante traz as situações vivenciadas para o espaço de discussão do estágio e busca na sua formação os elementos que Ihe permitam lidar com esta situação.

A partir desta premissa, as ações dos grupos do PIBID devem privilegiar por parte do Coordenador de Área um conjunto de situações do cotidiano escolar que satisfaçam ao critério de que seu enfrentamento pode ajudar, potencialmente, no desenvolvimento das competências e habilidades programadas para o período. Não escolhemos qualquer situação na escola para desenvolvermos ações dos grupos do PIBID.

Naturalmente que, na situação prática da escola recebemos demandas da direção e dos professores para o desenvolvimento de ações que buscam o enfrentamento de situações que são problemáticas na realidade escolar. Estas demandas devem ser aceitas como desafios nos grupos do PIBID desde que sejam alinhadas com a programação do grupo e contribuam para a formação docente dos acadêmicos do PIBID.

\section{A FORMAÇÃO ACONTECE NO PROCESSO DE REFLEXÃO SOBRE O REAL E NÃO NA AÇÃO SOBRE O REAL OU NA REFLEXÃO PURAMENTE TEÓRICA, DESCONTEXTUALIZADA DO REAL}

O momento da ação sobre a realidade escolar, embora componente importante dos grupos do PIBID, não esgota ou constitui a formação em si. A formação, entendida como um processo de apropriação consciente das relações envolvidas na ação, acontece quando os acadêmicos se apropriam da ação por meio da reflexão e da elaboração dos fatores que levaram a ação do grupo aos resultados obtidos. Neste sentido, não existe ação com sucesso ou insucesso em um grupo do PIBID, mas sim ações que propiciam diferentes tipos de reflexão sobre a realidade escolar. Ao se apropriarem por meio da via racional dos fatores envolvidos na ação, realizando as conexões com os conhecimentos docentes curriculares e com os conhecimentos docentes oriundos das diferentes práticas docentes, é que a verdadeira formação acontece. Somente sabendo porque algo "dá certo" e porque algo "dá errado" é que podemos reproduzir as condições do sucesso e evitar as condições que levaram ao insucesso da ação. Também é na reflexão sobre a ação que a tessitura Teoria - Prática se estabelece e estas duas entidades deixam de ser isoladas e passam a se constituir uma única entidade.

Como orientação para a ação dos diferentes grupos do PIBID, temos que nunca devemos passar para o desenvolvimento de uma nova ação antes que o processo de reflexão sobre a ação anterior tenha sido realizado. O PIBID não se desenvolve apenas pelo desenvolvimento de ações sobre o real. 


\section{O TRABALHO DOS ALUNOS DO PIBID NÃO SUBSTITUI O TRABALHO DOS PROFESSORES, MAS O TRABALHO DO PROFESSOR É O EIXO ARTICULADOR DAS AÇÕES DO PIBID}

Este é um ponto que, historicamente, tem sido um ponto de dúvidas e tensões no relacionamento dos grupos do PIBID com as escolas ${ }^{7}$. Por definição, o PIBID é um projeto de ensino voltado para a formação docente. Uma das premissas deste projeto de formação é que esta formação acontece no espaço da escola e, como corolário desta afirmação, os agentes escolares são parte do conjunto dos agentes responsáveis pela formação dos acadêmicos (outros são o Coordenador de Área e os professores do curso de formação). Portanto, o acadêmico do PIBID não pode substituir o seu formador e deve trabalhar sob supervisão e em estreito contato com este formador. Sendo assim, a ação dos pibidianos na escola sempre deve ser uma atuação assistida, jamais uma atuação solo. Também corolário da hipótese básica, de que o acadêmico do PIBID é um profissional em formação, o planejamento do ensino por ele construído deve ser sempre supervisionado pelos seus formadores (o Coordenador de Área e o professor da escola, seja ele o Supervisor ou não). Este planejamento deve acompanhar o planejamento do professor e complementá-lo. A consequência disto é que o acadêmico do PIBID não deve ser "usado" para substituir professor faltante (não importa a razão ou a situação), nas atividades extraclasse deve ser acompanhado pelo Supervisor ou pelo Coordenador de Área e assim por diante.

\section{A ESCOLA É UM ESPAÇO FORMATIVO EM TODAS AS SUAS DIMENSÕES, INDO ALÉM DA SIMPLES ATUAÇÃO NA SALA DE AULA OU EM ESPAÇOS ALTERNATIVOS NOS QUAIS A AÇÃO DIRETA COM OS ALUNOS ACONTEÇA}

Não se pode reduzir a escola, como espaço formador, apenas às ações em sala de aula com os alunos. A escola é um espaço rico em interações, locus da ação docente. Essas interações ocorrem em várias dimensões: na dimensão interpessoal, na dimensão das relações de poder, na dimensão das interações com o ambiente externo à escola, na dimensão das relações com o aparato do estado e assim por diante. O trânsito por estas diferentes dimensões nem sempre é tranquilo, gerando, muitas vezes, situações de tensão que devem ser manipuladas por profissionais que coabitam o espaço da escola e o futuro docente terá que transitar e aprender a lidar com elas ao longo de seu processo formativo para a vida profissional. Assim, reduzir a formação docente à interação com os alunos é privar o futuro docente de experiências ricas para a sua formação. Um grupo PIBID deve propiciar experiências e a reflexão sobre elas em todas estas dimensões.

Dentro desta linha de pensamento, um grupo de ações importantes é composto pelas ações que privilegiam a discussão destas dimensões. Por exemplo, a participação de alunos dos grupos do PIBID em espaços de discussão e tomada de decisão dentro da escola é fundamental (como o Conselho de Classe ou a Reunião do Conselho de Pais e Mestres) e deve ser parte integrante do processo formativo. 


\section{A AÇÃO DOS GRUPOS PIBID NA UFMS}

Mas como se dão os processos de interação entre a universidade e as escolas? Naturalmente, cada projeto do PIBID precisa desenvolver formas de estabelecer algum tipo de interação com as escolas, resultado do contexto cultural e histórico no qual o projeto se insere. Discorreremos aqui sobre a concepção que procuramos desenvolver na Universidade Federal de Mato Grosso do Sul (UFMS). Essa concepção se alicerça na ideia de que a relação com a escola deve ser uma relação de parceria e não de subordinação de uma a outra, em qualquer dos dois sentidos.

Os procedimentos de intervenção na realidade da escola pública têm por base uma metodologia similar à metodologia da Pesquisa Participante. Na perspectiva desse tipo de concepção, não cabe à universidade indicar, exclusivamente, a forma e o tema do processo de intervenção, cabendo aos docentes das escolas conveniadas a participação ativa nesse processo, indicando o que, a partir do seu ponto de vista, são as carências da escola na qual trabalham. À universidade cabe colocar suas competências nas atividades de planejamento, elaboração, orientação e execução das atividades com base nas informações fornecidas pelos docentes das escolas conveniadas sobre as carências que têm maior urgência de atendimento nas suas respectivas escolas. Naturalmente, que essa perspectiva teórica não impede a UFMS de propor soluções para problemas que somente podem ser percebidos por alguém que se localize externamente ao ambiente escolar e que faça uma reflexão sobre as práticas escolares de uma perspectiva externa e distanciada.

Nesta linha de pensamento, os projetos do PIBID da instituição privilegiam a integração entre atividades de extensão, ensino e pesquisa, baseando-se no tripé mostrado na Figura 1. Os três eixos de ação mostrados na figura se articulam e complementam.

Em um primeiro momento, toda ação dos grupos PIBID - UFMS parte de uma reflexão sobre a realidade escolar. Esta reflexão deve fugir do senso comum e ser embasada em algum referencial teórico que oriente a leitura de mundo e dirija o olhar, identificando possíveis problemas na realidade escolar e propondo ações para seu enfrentamento. Nesta etapa de leitura de mundo, a participação da comunidade escolar é fundamental. A comunidade escolar é que deve indicar quais são os pontos problemáticos na realidade analisada. Por essa razão, todos os projetos do PIBID - UFMS começam com um levantamento diagnóstico baseado no diálogo entre os atores na escola e os atores na universidade.

Fase fundamental, ela tem por objetivo colimar a atenção das duas comunidades e estabelecer um canal de diálogo entre a universidade e a escola, aproximando linguagens e olhares. Esta etapa também é fundamental para estabelecer o status dos diferentes atores no processo: os grupos do PIBID e os agentes escolares têm um mesmo status na detecção dos problemas. Com isso, os grupos do PIBID tratam de problemas que são vistos como tais pela comunidade escolar. 
Figura 1 - Eixos de Ação

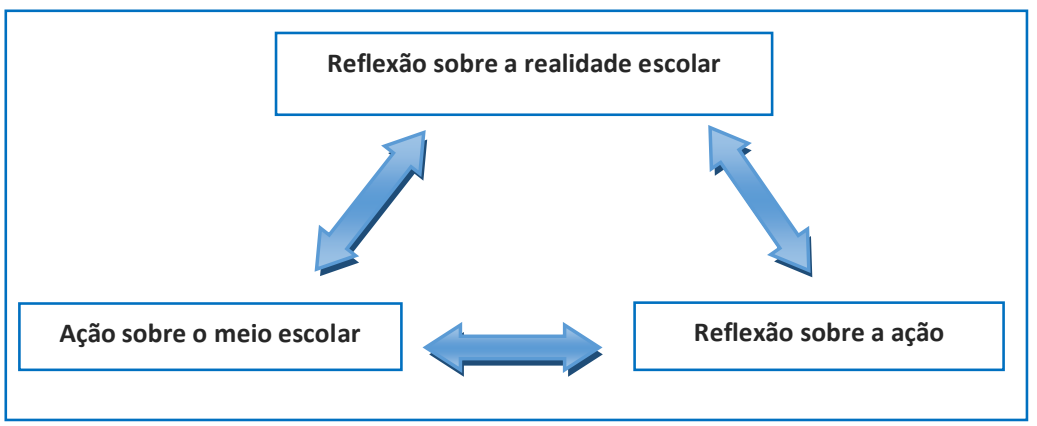

Fonte: Autoria própria (2016).

O segundo momento, chamado de Ação sobre o meio escolar, é caracterizado pelo desenvolvimento das atividades que foram planejadas para o enfrentamento das situações problema identificadas na primeira fase. Consiste no desenvolvimento de atividades de ensino no ambiente escolar. Esta é a parte mais visível para a comunidade escolar da ação do PIBID - UFMS. Este é um ponto delicado, uma vez que as ações desenvolvidas pelos grupos PIBID - UFMS devem, ao mesmo tempo, agir sobre e serem integradas à realidade escolar. Por "agir sobre", queremos dizer que estas ações são práticas visando à modificação da realidade encontrada, levando à superação de obstáculos. Por "serem integradas à", entendemos que estas ações deveriam ser incorporadas às práticas dos docentes das escolas envolvidas, objetivando evitar o aparecimento da mesma problemática em outros alunos. Assim, por exemplo, uma ação de recuperação escolar em Matemática age sobre a comunidade escolar, levando aqueles alunos que participam da atividade de recuperação a superarem suas dificuldades. Por outro lado, também, estas metodologias e materiais, se forem apropriados pelos professores de Matemática da escola envolvida, levarão à superação no ambiente da sala de aula das dificuldades observadas em relação àquele conteúdo (e, portanto, eliminando a necessidade de oferecimento de nova ação de recuperação).

Nesta fase, se materializa uma das mais importantes metas do PIBID: a transformação do espaço escolar em um espaço de formação do futuro docente. Este ponto é sensível, uma vez que é grande a possibilidade de que a ação dos alunos se confunda com ações típicas das Práticas do Ensino e do Estágio Curricular. Se por um lado as ações dos alunos do PIBID têm características comuns às ações dos outros tipos de intervenção na escola, não podemos esquecer que o aluno do PIBID é um docente em formação. Ele ainda está se apropriando dos referenciais teóricos ligados ao ensino (domínio didático), ao mesmo tempo em que se apropria dos conteúdos específicos da sua disciplina (domínio do conteúdo a ser ensinado). Neste ponto, o aluno do Estágio é um contraponto interessante: este, em tese, já se apropriou dos conhecimentos dos dois domínios e no Estágio procura a sua integração. Além dessa diferença, há outra: o aluno do PIBID atua sempre sob supervisão do Coordenador de Área (docente da UFMS) e do Supervisor da escola, desde a fase de planejamento até a fase de avaliação da atividade desenvolvida. Observe-se que, no Estágio, esta relação é mais distante, usualmente as aulas sendo preparadas na universidade e desenvolvidas na escola, a interação se dando no plano da inserção das aulas de estágio no planejamento do professor supervisor de estágio. Além disso, o PIBID 
traz a intencionalidade de fornecer capacitação em serviço ao Supervisor, intencionalidade não presente no Estágio ${ }^{8}$.

Há, ainda, outro ponto de divergência entre as ações do PIBID e do Estágio: as ações no PIBID são projetadas para explorarem situações que possibilitem a discussão e a reflexão sobre a escola. A situação particular é escolhida e alguma ação executada por possibilitar a exploração de algum aspecto didático ou do ambiente escolar que vai possibilitar a discussão e a reflexão dentro do grupo. A situação é uma ferramenta selecionada para desenvolver algum aspecto da formação do futuro professor. No Estágio, por outro lado, o aluno é inserido em um contexto de "produção", isto é, em situações didáticas ditadas pela conveniência da escola, no sentido de que as ações do estagiário se subordinam ao planejamento do docente da escola, e não, necessariamente, pela conveniência da formação. Assim, no Estágio a situação particular é objeto.

O terceiro momento de qualquer ação do PIBID - UFMS é a Reflexão Sobre a Ação. Não basta agir: é preciso refletir sobre a ação. Neste momento, o referencial teórico que orientou a leitura de mundo e o delineamento da ação desenvolvida deve ser retomado e uma análise criteriosa, usando das ferramentas disponíveis na área de pesquisa em Ciências Sociais, deve ser realizada. A pergunta básica a ser respondida é:

A ação desenvolvida resultou na superação da situação detectada como problemática no primeiro momento?

Secundária a esta questão temos outras:

Quais as razões do sucesso ou do insucesso da ação desenvolvida?

O Referencial Teórico foi suficiente para a compreensão do fenômeno ou outros elementos teóricos devem ser buscados?

Como as ações desenvolvidas se articulam com os saberes docentes trabalhados nas disciplinas ao longo do curso de formação?

Com base nas respostas a estas questões (e outras que surgem do embate entre a teoria estudada nos cursos de licenciatura e a realidade escolar) as ações podem ser retomadas ou, se os resultados obtidos se mostrarem satisfatórios, incorporadas às práticas dos docentes da escola.

Esta incorporação das metodologias e materiais instrucionais às práticas docentes da escola é algo que depende da intencionalidade e da mobilização dos docentes da disciplina envolvida e tem se apresentado um dos pontos nos quais a proposta do PIBID - UFMS se mostra incompleta. Este é um ponto que merece reflexão e estudo, uma vez que esta apropriação pelos docentes das escolas das metodologias e materiais instrucionais tem sido, em geral, insatisfatória. As razões necessitam ser mais estudadas e não nos atreveremos a enunciar nenhuma aqui.

Um elemento novo introduzido na proposta do PIBID - UFMS, fruto da reflexão sobre os projetos já implantados, diz respeito à intencionalidade explícita de fornecer formação política aos acadêmicos-docentes ${ }^{9}$. Como dissemos anteriormente, esta formação política surge da necessidade de ampliar o entendimento do que seja a função docente. Esta tem sido entendida de uma forma stricto sensu, no sentido de que a função docente se esgota em atividades 
de natureza didática, aquelas nas quais os docentes se preocupam com o trabalho com os alunos, seja de forma direta (como em atividades de regência) seja na forma indireta (como na preparação de materiais instrucionais). Entretanto, o campo escolar não se esgota nestes tipos de atividades, tendo elementos de naturezas política e ideológica que determinam o ambiente no qual o acadêmico-docente vai ser inserido. A compreensão das interações de natureza social, que muitas vezes envolvem questões de disputa de poder, necessita de uma formação política, entendida como aqueles conhecimentos derivados da Sociologia, da Filosofia e da Ciência Política que permitam ao acadêmico-docente a percepção e a compreensão destas relações. Por conta disto, a função docente também se exerce em outros espaços que o da sala de aula, tais como os conselhos de classe, a sala de professores, a reunião de pais e mestres, a reunião da associação de bairro, reuniões sindicais e assim por diante. Cremos ser fundamental para a formação do futuro docente a vivência pelo acadêmicodocente destes espaços de discussão (e de disputa política) e a posterior reflexão sobre suas observações.

Outro ponto importante, também derivado de nossa experiência com os projetos já implantados, é a necessidade de uma ação efetiva dentro dos grupos PIBID que procure integrar as disciplinas de conteúdo pedagógico, entendidas como aquelas que lidam com o como fazer o ensino, com as disciplinas que lidam com os conteúdos a serem ensinados. Esta separação em dois grupos de disciplinas é resultado da própria estrutura dos cursos de licenciatura, nos quais, normalmente, as disciplinas de conteúdo específico não incorporam o fazer docente e as disciplinas pedagógicas não se preocupam em sanar deficiências dos estudantes em conteúdos a serem ensinados. Isto se manifesta nos curricula da maior parte das licenciaturas, nos quais a Prática de Ensino aparece na forma de disciplinas isoladas das disciplinas de conteúdo a ser ensinado e não na forma de uma componente curricular das diferentes disciplinas do currículo, com os conhecimentos pedagógicos do como ensinar no mesmo nível dos conteúdos a serem ensinados. Os grupos PIBID devem romper esta dicotomia, trazendo para a discussão dentro dos coletivos as relações entre estes dois grupos de disciplinas e as formas de integração entre eles.

Ainda resultado de nossa experiência com grupos PIBID, acreditamos que a interdisciplinaridade deva ser fortemente enfatizada como princípio orientador à concepção e à ação dos grupos PIBID. Como linha geral de ação, as equipes de acadêmicos-docentes deveriam trabalhar, quando possível e em temáticas que o permitam, de forma interdisciplinar, abordando temas específicos de cada disciplina bem como temas de natureza transversal como, por exemplo, a Educação Ambiental. Por essa razão, sempre que possível, os grupos PIBID deveriam desenvolver projetos conjuntos na mesma cidade e, quando possível, na mesma escola. Contudo, esse aspecto do PIBID - UFMS continua sendo uma utopia, muito por conta dos próprios Coordenadores de Área que não têm na abordagem interdisciplinar a principal forma de trabalhar nos cursos de Licenciatura. No âmbito do PIBID - UFMS estamos trabalhando para romper com a divisão curricular e desenvolver algumas atividades interdisciplinares.

Este último ponto serve como elemento condutor aos quatro primeiros. Dentro dessa perspectiva o esquema mostrado na Figura 2 explicita as ações a serem desenvolvidas. 
Nas ações desenvolvidas, os acadêmicos-docentes desenvolvem atividades visando a articular a universidade com as escolas, introduzindo no cotidiano escolar a produção dos cursos de licenciatura, tanto os materiais didáticos produzidos nas diferentes licenciaturas como resultados de pesquisa sobre metodologias de ensino, como a produção de materiais específicos para atender necessidades localizadas das escolas. São promovidas reflexões sobre a formação inicial dos licenciandos e a realimentação das práticas ligadas à formação continuada dos professores das escolas envolvidas no projeto.

Figura 2 - Ações a Serem Desenvolvidas no Pibid

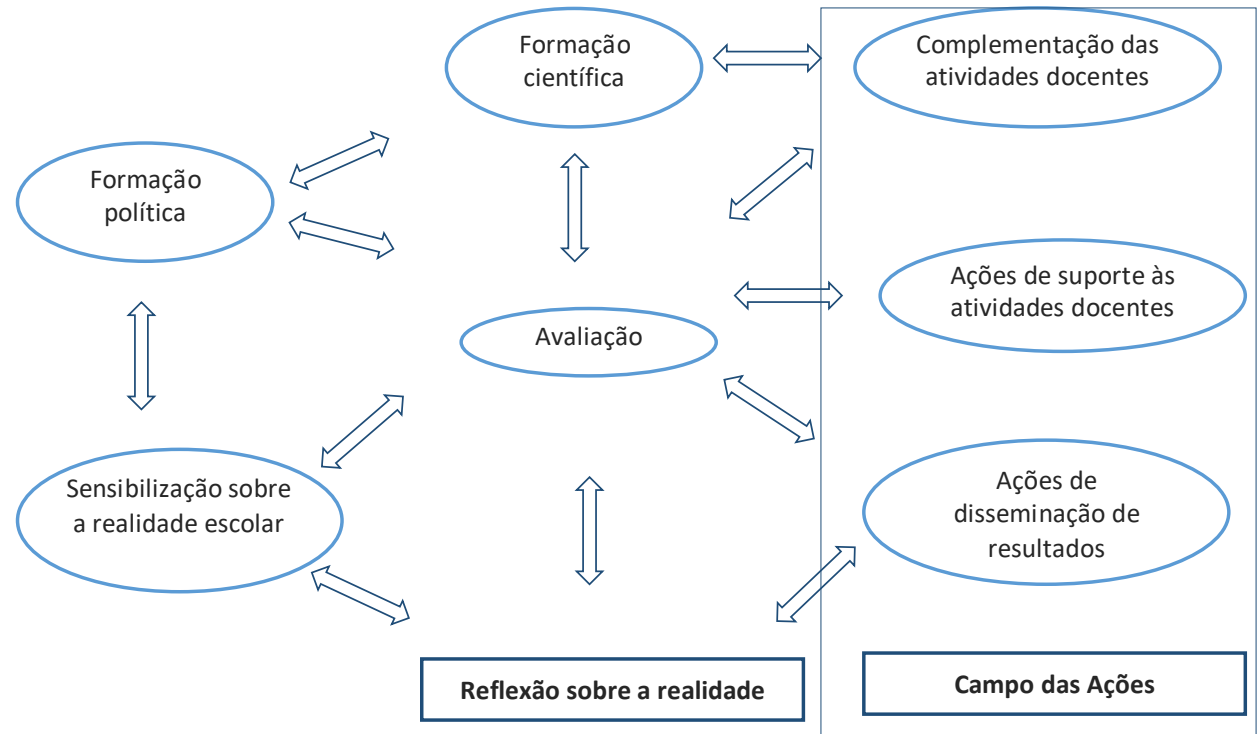

Fonte: Autoria própria (2016).

\section{REMODELANDO A FORMAÇÃO DOCENTE}

Podemos ver, então, a partir da descrição e do modelo do PIBID, que esse Programa e as formas como se desdobra na sua relação com a escola, oferece um novo modelo ou novos paradigmas para a formação docente. Primeiro, porque inverte a lógica da formação, ao colocar a experiência docente na escola como ponto de partida nos processos formativos. Segundo, por incorporar ao longo de todo o trabalho de formação a escola como o locus privilegiado da formação docente. Terceiro, por incorporar no corpus de conhecimentos a ser construído pelos estudantes os conhecimentos docentes construídos a partir de sua prática. Por fim, mas não menos importante, por tornar os docentes das escolas parceiros no processo de formação.

Cremos que esses quatro paradigmas, se incorporados de forma sistemática aos nossos programas de formação inicial de docentes ajudarão a qualificar esta formação e a diminuir os impactos sobre os futuros docentes da inserção no mercado de trabalho, ajudando-os a superarem essa difícil etapa na qual o estranhamento causado pela formação ministrada hoje nos cursos de formação de professores é causa de abandono e desestímulo para a carreira docente.

Por outro lado, quais as consequências para os cursos de formação para a docência? Nos parece claro que o atual modelo disciplinar, mesmo baseado na 
completa implementação das Práticas de Ensino como Componentes Curriculares, não poderia dar conta de um processo formativo como o desenvolvido no PIBID. Observe-se que, no PIBID, a aprendizagem dos conteúdos a serem ensinados, as Práticas de Ensino, o Estágio, o diálogo com os saberes escolares construídos pelos docentes e a reflexão profunda sobre o ser docente, no sentido lato sensu, como discutido nesse trabalho, ocorrem ao mesmo tempo e no mesmo espaço formativo. Consequentemente, para que uma proposta de organização curricular como essa pudesse ser implementada, os cursos de formação deveriam ser organizados por projetos e não mais como disciplinas, o que, claramente, é uma ruptura paradigmática com a forma como os cursos são organizados em nossas universidades.

Talvez um caminho intermediário pudesse ser trilhado, associando projetos a serem desenvolvidos pelos estudantes no espaço escolar ao longo do percurso formativo.

Esse talvez seja o maior desafio aos responsáveis pelos currículos dos cursos de formação de professores: incorporar a rica experiência representada pelo PIBID aos cursos de formação, de modo a repensar esse processo na direção de uma formação que esteja mais próxima do locus da ação do futuro docente. 


\title{
The Institutional Program of Educational Scholarships for Teachers: a new paradigm for teacher education?
}

\begin{abstract}
In this article, we discuss the different aspects of teacher training education in the universities of Brazil and the characteristics of the "Programa Institucional de Bolsas de Iniciação à Docência" (PIBID) - The Institutional Program of Educational Scholarships for Teachers. PIBID is a public program funded by Brazilian agency CAPES whose main goal is to stimulate young students following undergraduate courses, encouraging them to choose to study education and end up as teachers in the public education system. The main characteristic of PIBID is to use public school environment as a place for training these new teachers in a way they can learn with experienced teachers the means, or strategies that they have been developing along their careers, and which are absent from the curriculum of the university. Besides, PIBID promotes a direct contact between these students and the school environment giving them the opportunity to experience the real life of what may be there future profession. We propose the PIBID pattern as a new paradigm for teacher education in universities.
\end{abstract}

KEYWORDS: PIBID. Teacher training. 


\section{NOTAS}

1 Os pibidianos.

2 Neste texto, faremos diferenciação entre conhecimento e saber. Conhecimento definimos como um conjunto de asserções, de conhecimento ou valor, que podem ser enunciados no processo de ensino. Saber é oriundo da interação entre esse conjunto de asserções e as experiências do sujeito que as recebe, nascendo como uma síntese dialética dessa interação.

30 professor ensina como aprende.

4 Um exemplo deste tipo de situação idealizada são os minicursos muitas vezes usados nos cursos de formação de professores ao longo das disciplinas de estágio supervisionado. Nestas situações, os futuros professores ficam completamente apartados da dinâmica real da sala de aula, nas quais o conflito muitas vezes é a tônica.

5 Chamamos, em outro texto, a este corpo de conhecimentos de Pedagogia Privada (ROSA, 2011).

6 Uma fonte importante desse conhecimento é a produção dos cursos de Mestrado Profissional na área de Ensino.

$7 \mathrm{Um}$ exemplo disso é o processo de enfrentamento desencadeado pela Portaria 46 de 2016 da CAPES, revogada depois de muita pressão, que alterava fundamentalmente a concepção do PIBID, transformando os acadêmicos em extensões do corpo docente das escolas.

8 Este ponto foge ao escopo desse artigo. Entretanto, é um dos pontos mais interessantes do PIBID.

9 No projeto PIBID - UFMS os acadêmicos são chamados de acadêmicosdocentes para evidenciar o duplo papel que desempenham no PIBID. O termo pibidiano também tem sido utilizado.

\section{REFERÊNCIAS}

BOURDIEU, P.; PASSERON, J. C. Reprodução: elementos para uma teoria do sistema de ensino. 3 ed. ed. Rio de Janeiro: Francisco Alves, 1992. 238 p.

BRASIL. MEC. CAPES. Seleção pública de propostas de projetos de iniciação à docência voltados ao Programa Institucional de Iniciação à Docência - PIBID, Edital MEC/CAPES/FNDE. Brasília: [s.n.], 2007.

BRASIL. MEC. CAPES. Programa Institucional de Bolsa de Iniciação à Docência, Edital Capes/deb № 02/2009 - PIBID. Brasília: [s.n.], 2009.

BRASIL. MEC. CAPES. Portaria n. 72 Da nova redação a Portaria que dispõe sobre o Programa Institucional de Bolsa de Iniciação à Docência - PIBID, no âmbito da 
BRASIL. MEC. CAPES. Portaria n. 260. Brasília: [s.n.], 2010b.

BRASIL. MEC. CAPES. Portaria n. 096/2013. Brasília: [s.n.], 2013.

BRASIL. MEC. CNE. Parecer $\mathbf{n} .28$ de 02 de outubro de 2001, CNE/CP. Brasília: [s.n.], 2001.

GAUTHIER, C. et al. Pour une théorie de la pédagogie-Recherches contemporaines sur lês avoir desenseignants. Laval: Le Presses de I'Université, 1997. (Perspectives en Education).

ROSA, P. R. S. Instrumentação para o Ensino de Ciências. Campo Grande: Editora da UFMS, 2011.

SCHÖN, D. A. Educando o profissional reflexivo: um novo design para o ensino e a aprendizagem. Tradução de Roberto Cataldo Costa. Porto Alegre: Artmed Editora, 2000.

TARDIF, M. Saberes Docentes e Formação Profissional. 8a ed. Ed. Petrópolis: Editora Vozes, 2007. 325 p.

ROSA, P. R. da S. O programa institucional de bolsas de iniciação à docência: um novo paradigma para a formação de professores?. ACTIO, Curitiba, v. 1, n. 1, p. 51-69, jul./dez. 2016. Disponível em:

<https://periodicos.utfpr.edu.br/actio>. Acesso em: XXX.

Correspondência:

Paulo Ricardo da Silva Rosa Instituto de Física da UFMS

Cidade Universitária, Caixa Postal 549, CEP 79070-900, Campo Grande, Mato Grosso do Sul, Brasil. Direito autoral: Este artigo está licenciado sob os termos da Licença CreativeCommons-Atribuição 4.0 Internacional.

\section{(c) (1)}

